\title{
A Code for Behavioral Inhibition on the Basis of Color, But Not Motion, in Ventrolateral Prefrontal Cortex of Macaque Monkey
}

\author{
Masamichi Sakagami, ${ }^{1,2}$ Ken-ichiro Tsutsui, ${ }^{3}$ Johan Lauwereyns, ${ }^{1}$ Masashi Koizumi, ${ }^{1}$ Shunsuke Kobayashi, ${ }^{4}$ \\ and Okihide Hikosaka ${ }^{1}$
}

${ }^{1}$ Department of Physiology, Juntendo University, School of Medicine, Bunkyo, Tokyo, Japan 113-8421, ${ }^{2 B}$ Brain Science

Research Center, Tamagawa University, Machida, Tokyo, Japan 194-8610, ${ }^{3}$ Department of Physiology, Nihon University, School of Medicine, Itabashi, Tokyo, Japan 173-8610, and ${ }^{4}$ Department of Neurology, University of Tokyo, School of

Medicine, Bunkyo, Tokyo, Japan 113-8655

\begin{abstract}
To examine the neural mechanism for behavioral inhibition, we recorded single-cell activity in macaque ventrolateral prefrontal cortex, which is known to receive visual information directly from the inferotemporal cortex. In response to a moving random pattern of colored dots, monkeys had to make a go or no-go response. In the color condition, green indicated go, whereas red indicated no-go, regardless of the motion direction; in the motion condition, upward indicated go, whereas downward indicated no-go, regardless of the color. Approximately one-half of the visual cells were go/no-go differential. A majority of these cells (64/73) showed differential activity only in the color condition; they responded nondifferentially in the motion condition, although the same set of stimuli was used. We classified these cells as "go type" $(n=41)$ and "no-go type" $(n=23)$ depending on the color for which they showed a stronger response. Interestingly, in both types of cells, the differential effects were observed only for the no-
\end{abstract}

It is thought that the lateral prefrontal cortex (LPFC) has an important role in selecting an appropriate response on the basis of external sensory stimuli, particularly when the same stimulus can require a different response depending on the context. Many studies have suggested that several possible functions contribute to this process: working memory (Goldman-Rakic, 1987), detection of behavioral meaning (Watanabe, 1986), temporal integration (Fuster, 1997), sensory-motor integration (Kim and Shadlen, 1999), and attention to action (Passingham, 1998).

Inhibitory control over the response-selection process seems to be another important function of the LPFC. Patients with prefrontal pathology have difficulty in inhibiting inappropriate behavior in a given context (Luria, 1966; Lhermitte et al., 1986; Shimamura, 1994; Fuster, 1997; Knight et al., 1999). In experimental situations such as the anti-saccade eye movement task (Guitton et al., 1985), the Stroop task (Perret, 1974), and the go/no-go task (Drewe, 1975), prefrontal patients are often unable to suppress prepotent responses evoked by irrelevant stimuli.

\footnotetext{
Received Dec. 12, 2000; revised April 4, 2001; accepted April 5, 2001.

This research was supported by grants from Core Research for Evolution Science and Technology, Japan Society for the Promotion of Science, and the Ministry of Education, Culture, Sports, Science, and Technology of Japan. We thank Hiroaki Niki for his advice on this research.

Correspondence should be addressed to Masamichi Sakagami, Brain Science Research Center, Tamagawa University, Tamagawa-gakuen 6-1-1, Machida, Tokyo 194-8610, Japan. E-mail address: sakagami@lab.tamagawa.ac.jp.

Copyright (c) 2001 Society for Neuroscience 0270-6474/01/214801-08\$15.00/0
}

go-indicating color. Compared with the nondifferential responses in the motion condition, go-type cells in the color condition showed weaker responses to the no-go-indicating color, whereas their responses to the go-indicating color were similar; in contrast, no-go type cells showed stronger responses to the no-go-indicating color, whereas their responses to the go-indicating color were similar. Both types of cells did not show any activity change during the actual execution of the go or no-go response. These results suggest that neurons in ventrolateral prefrontal cortex contribute to stimulus-response association in complex task situations by inhibiting behavioral responses on the basis of visual information from the ventral stream.

Key words: inhibitory control; ventrolateral prefrontal cortex; macaque monkey; go/no-go task; selective attention; color; random dot motion; single unit; ventral pathway
Although it is difficult to tell from these human clinical studies which area in LPFC is related to the inhibitory control, experimental lesion studies with nonhuman primates have suggested one candidate area in LPFC, that is, the ventrolateral part of prefrontal cortex (VLPFC) (Butter, 1969; Iversen and Mishkin, 1970; Butters et al., 1973; Passingham, 1975; Mishkin and Manning, 1978; Dias et al., 1996).

It remains unknown, however, how neurons in VLPFC behave to exert the presumed inhibitory control. Single-unit studies with monkeys have suggested that prefrontal cortex converts sensory information into commands for appropriate behavioral output (Komatsu, 1982; Watanabe, 1986; Yajeya et al., 1988; Niki et al., 1990; Yamatani et al., 1990; Schall and Hanes, 1993; Sakagami and Niki, 1994a; Asaad et al., 1998; Rainer et al., 1998; Ferrera et al., 1999; Kim and Shadlen, 1999; Sakagami and Tsutsui, 1999). However, there has been no indication that prefrontal neurons are related to stimulus-response association based on inhibitory control. Specifically, a majority of neurons in LPFC, including VLPFC, responded to a stimulus that instructed execution, not suppression, of a behavioral response (Watanabe, 1986; Niki et al., 1990; Sakagami and Niki, 1994a; Sakagami and Tsutsui, 1999).

To resolve this issue, we recorded single-unit activity from VLPFC of two Japanese monkeys while they performed a manual go/no-go task in response to either the color or motion of a visual stimulus. Many VLPFC neurons showed differential go/no-go activity in response to color but not motion direction (Sakagami 
and Tsutsui, 1999). As in the previous studies, a majority of the neurons showed higher activity for the go-indicating stimuli. However, by comparing the activity pattern of the neurons between different attention conditions, we reached a different conclusion: VLPFC neurons indicate the behavioral meaning of color by changing their activity only for the color that requires a no-go response.

\section{MATERIALS AND METHODS}

Subjects. We used two male Japanese monkeys (Macaca fuscata). All surgical and experimental protocols were approved by the Animal Care and Use Committees at the University of Tokyo and Juntendo University and were in accordance with guidelines set by the National Insititutes of Health.

Behavioral paradigm. The monkey was required to make a go or no-go response depending on either the color or the motion direction of the target stimulus (see Fig. 1). The monkey initiated each trial with a lever press (a small plastic disk, $2.0 \mathrm{~cm}$ in diameter, attached to the monkey chair in front of the right hand at the height of the animal's elbow). A fixation spot $\left(0.3^{\circ}\right.$ in diameter $)$ appeared in the center of the 20 inch cathode ray tube with a $60 \mathrm{~Hz}$ refresh rate (HC39PEX, Mitsubishi) that was placed directly in front of the monkey. After a variable period (1-2 $\mathrm{sec}$ ), the target stimulus was presented for $200 \mathrm{msec}$ at one of four locations $\left(4.1^{\circ}\right.$ from the fixation spot, above, below, to the right, or to the left). After a variable delay $(0.5-2 \mathrm{sec})$, the fixation spot dimmed. For a correct go response, the monkey had to release the lever within $0.8 \mathrm{sec}$. For a correct no-go response, the monkey had to refrain from releasing the lever for at least $1.2 \mathrm{sec}$; the monkey could release the lever at any time after the $1.2 \mathrm{sec}$ no-go period. A drop of fruit juice was delivered after the lever release as reward for every correct go or no-go response. This task can be regarded as a delayed version of a symmetrically rewarded go/no-go task because it is crucial for the monkey to associate the target stimulus with either releasing ("go") or not releasing ("no-go") the lever within the response period.

We used the delayed version of the symmetrically rewarded go/no-go task to exclude confounding factors. First, the monkey was rewarded also in the no-go trial after releasing the lever any time after the designated go response period. This was done to exclude differential neuronal activity related to expectation of reward. Such reward-related activity has been observed in many brain regions, including the prefrontal cortex (Watanabe, 1996; Leon and Shadlen, 1999; Tremblay and Schultz, 1999). Second, a delay period was inserted between target presentation and the imperative cue (fixation spot dimming). This was done to exclude activity related to motor processes; otherwise, the go-related response could simply be such motor-related activity.

The monkey viewed a dynamic random dot pattern through a virtual square aperture $\left(6.2 \times 6.2^{\circ}\right)$ as a target stimulus. All dots were of the same color and moved unidirectionally and coherently. Approximately 280 dots moving at $6 \% \mathrm{sec}$ were used to cover $11 \%$ of the virtual aperture area. Apparent motion was produced by successive replacement of four frames. Duration of each frame was $50 \mathrm{msec}$ (three ticks of $16.7 \mathrm{msec}$ refresh rate), and total presentation time was $200 \mathrm{msec}(50 \mathrm{msec} \times$ four frames). A yellow fixation spot signaled the color condition; a purple spot signaled the motion condition. All stimuli were otherwise the same in both conditions (see Fig. $1 B$ ). In the color condition, a green target indicated go, and a red target indicated no-go. In the motion condition, upward movement indicated go, and downward movement indicated no-go. Therefore we call green, in this example, "go color," red "no-go color," upward movement "go motion," and downward movement "no-go motion." To confirm that the neuronal response of the VLPFC cells did not depend merely on the physical properties of stimuli, in some cases additional data were collected in another two blocks with a different stimulus set (second set; purple or yellow target dots, leftward or rightward motion).

The $x$ and $y$ values of the Commission Internationale de l'Eclairage standard colorimetric system and the luminance for each color dot were as follows: $0.295,0.599,18.4 \mathrm{~cd} / \mathrm{m}^{2}$ for green (go color); $0.636,0.326,17.7$ $\mathrm{cd} / \mathrm{m}^{2}$ for red (no-go color); $0.279,0.132,22.4 \mathrm{~cd} / \mathrm{m}^{2}$ for purple (go color); and $0.415,0.504,23.2 \mathrm{~cd} / \mathrm{m}^{2}$ for yellow (no-go color). In this way, the luminance relations between go colors and no-go colors were counterbalanced between the two stimulus sets.

For monkey 2, the go and no-go responses were swapped: go colors were red and yellow, and no-go colors were green and purple; in the motion condition, rightward and downward movement required a go response, whereas leftward and upward movement required a no-go response.

From $500 \mathrm{msec}$ before until $500 \mathrm{msec}$ after the onset of the target stimulus, eye movements were restricted to within $1^{\circ}$ of the fixation spot by means of an infrared camera and associated equipment (R-21C-A, RMS). The sampling rate was $250 \mathrm{kHz}$.

At the end of the training, both monkeys performed this task with $>90 \%$ correct rate (collapsed across go and no-go trials) in both the color and motion condition (monkey 1, 96.2\% in the color condition and 94.2\% in the motion condition; monkey $2,98.1 \%$ in the color condition and 93.5\% in the motion condition). Training procedures and behavioral data with this paradigm have been described in detail elsewhere (Sakagami and Tsutsui, 1999; Lauwereyns et al., 2000).

Recording and histology. After completion of the training, we implanted a head-fixation device and unit-recording chamber and recorded single-unit activity from VLPFC of the two monkeys while they performed the task.

Recording was conducted in two blocks of 32-64 trials, one block in the color condition and one block in the motion condition. Within a block we did not change the attention condition; the order of blocks was randomized. Because some VLPFC cells show a spatial preference similar to the receptive fields found in visual cortices (Sakagami and Niki, 1994b), we presented the target stimuli at the one location, of four, where the cell showed the largest change in activity during preliminary investigation.

Recording locations were reconstructed by means of histology. Procedures for surgery, recording, and histology were the same as in our previous study (Sakagami and Niki, 1994a).

Data analysis. In this study we analyzed the activity of the cell immediately after visual target presentation. To analyze cell activity, a twofactor ANOVA [color (green vs red) $\times$ motion direction (upward vs downward)] was applied to the activity of the cell (100-300 msec period from target onset) separately for each block (color condition and motion condition). According to the results of ANOVAs, we selected cells showing go/no-go differential activity only in the color condition (taskdependent color cells; C cells). To understand the suppression and enhancement effects between different attention conditions, we used visual responses $(100-300 \mathrm{msec}$ after target onset) to compute task relevancy $(R)$ indices for both go $\left(R_{\mathrm{go}}\right)$ and no-go $\left(R_{\mathrm{ng}}\right)$ colors: $R_{\mathrm{go}}=$ $[\mathrm{go}(\mathrm{C})-\mathrm{go}(\mathrm{M})] /[\mathrm{go}(\mathrm{C})+\mathrm{go}(\mathrm{M})]$ and $R_{\mathrm{ng}}=[\operatorname{ng}(\mathrm{C})-\operatorname{ng}(\mathrm{M})] /[\operatorname{ng}(\mathrm{C})+$ $\mathrm{ng}(\mathrm{M})]$, where go(C) is activity to a go color in the color condition, $\mathrm{go}(\mathrm{M})$ is activity to a go color in the motion condition, $\mathrm{ng}(\mathrm{C})$ is activity to a no-go color in the color condition, and $\mathrm{ng}(\mathrm{M})$ is activity to a no-go color in the motion condition.

\section{RESULTS}

We recorded single-unit activity from two monkeys while they performed a manual go/no-go task in which they had to discriminate one feature of a multidimensional visual stimulus (a virtual square in which moving colored dots appeared; henceforth "target"). To obtain reward in the color condition, the monkey had to make a go response (immediate lever release) if the target was green (go color), whereas it had to make a no-go response (delayed lever release) if the target was red (no-go color), ignoring the motion direction of the target (Fig. $1 B$ ). In the motion condition, on the other hand, the monkey had to differentiate the motion direction of the target, whereas go and no-go colors were now irrelevant to the selection of the appropriate behavioral response.

While the monkeys performed the task in the two discrimination conditions, we recorded neuronal activity from the VLPFC, mainly in area 46 ventral to the sulcus principalis, the upper part of area 12, and the anterior part of area 45. Many cells change their activity in response to the presentation of the visual target immediately after its onset. We recorded 147 visually responsive cells that increased their activity following target presentation. Among the 147 visually responsive cells, 119 showed a statistically reliable main effect of two-factor (color vs motion) ANOVA $(p<0.01)$ in at least one of the conditions: color or motion, or 


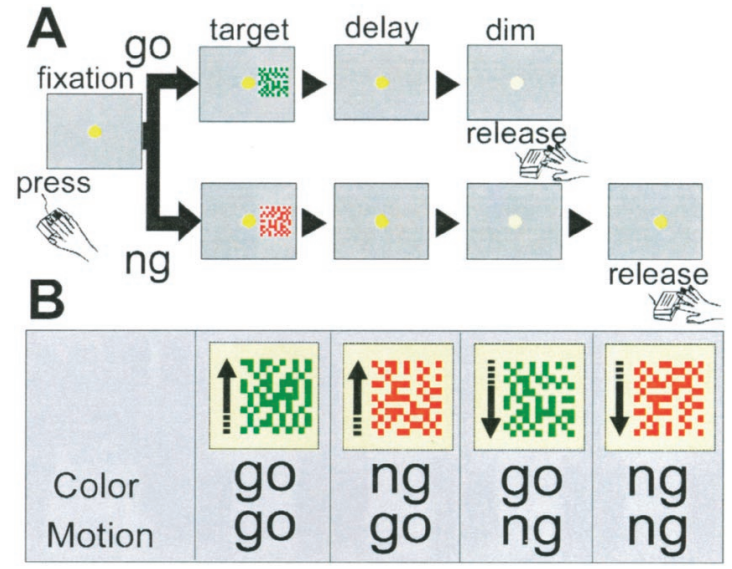

Figure 1. Schematic illustration of the experimental design and target stimuli. $A$, The trial began when the monkey pressed the lever. The monkey was required to focus his gaze at the fixation spot. A target cue was then presented for $200 \mathrm{msec}$, followed by a random delay period $(0.5-2 \mathrm{sec})$, until the fixation spot dimmed. If the target indicated a go response, the monkey had to release the lever immediately (within 0.8 $\mathrm{sec}$ ). If the target indicated a no-go response, the monkey had to continue to press the lever throughout the dim period $(1.2 \mathrm{sec})$, and then the fixation spot was re-illuminated. In no-go trials, the monkey could release the lever at any time after the dim period. Correct responses in both go and no-go trials were rewarded with a drop of orange juice immediately after the lever was released. $B$, Examples of target cues. The stimulus consisted of a moving random pattern of colored dots, green or red, and upward or downward direction. The color of the fixation spot indicated the attention condition. In the color condition (yellow fixation spot), a green target color indicated a go response, and a red target color indicated a no-go response. In the motion condition (purple fixation spot), upward motion direction indicated a go response, and downward movement indicated a no-go response.

both. Three of them decreased their activity on target presentation; these were excluded from further analyses. As shown in Table 1, we classified the cells according to the results of ANOVA as follows: (1) task-dependent color and motion go/no-go cell ("CM cell"; $n=6$ ), (2) task-dependent color go/no-go cell ("C cell"; $n=64)$, (3) task-dependent motion go/no-go cell ("M cell"; $n=3$ ), (4) task-independent color cell ("CI cell"; $n=14$ ), and (5) task-independent motion cell ("MI cell"; $n=0$ ). The remaining 29 cells showed complex activity patterns that we could not classify. As we suggested previously (Sakagami and Tsutsui, 1999), the largest group of visually responsive cells in VLPFC was that of task-dependent color go/no-go cells (C cells), which show a significant main effect of color in the color condition, without any other reliable main effect. Among $\mathrm{C}$ cells, three showed a significant interaction effect $(p<0.01)$ between the color and motion factors. In this report, we will concentrate on $\mathrm{C}$ cells.

We illustrate the activity pattern of a typical C cell in Figure 2. The cell showed a selective increase in activity for targets with a go color (green) when the monkey performed the discrimination task in response to the color of the target (Fig. 2A, left panel). In the motion condition, however, the activity of the same cell did not differ between colors or motion directions of the targets (Fig. $2 A$, right panel). In the rasters and histograms aligned on lever release, no change of activity can be observed around the execution of the manual response. This cell, then, seems to code the task-relevant meaning (go or no-go) of the color features, rather than the preparation or execution of the specific motor command. Using another set of stimuli (purple vs yellow, leftward vs right- ward movement) with the same $\mathrm{C}$ cell, we could confirm that its representation of behavioral significance did not depend on any specific color (Fig. 2B). Of $64 \mathrm{C}$ cells, 41 cells responded more to targets with a go color than to targets with a no-go color, as shown in Figure 2 (go type: $64.1 \%$ ); the remaining $23 \mathrm{C}$ cells responded more to targets with a no-go color than to targets with a go color, as shown in Figure 3 (no-go type: $35.9 \%$ ).

For 25 go type and 18 no-go type C cells, we were able to repeat the entire experiment with the second set of stimuli. Using the same analysis as for the first set of stimuli with two-factor ANOVAs, we checked the consistency of neuronal activity between the first and second set of stimuli. Among 25 go type $\mathrm{C}$ cells, 19 cells showed differential activity for go and no-go colors with the second set of stimuli in the color condition; all but one of them $(18 / 19 ; 94.7 \%)$ showed stronger activity for the go color, consistent with their go type activity with the first set of stimuli. Among 18 no-go type C cells, 16 cells showed differential activity for go and no-go colors with the second set of stimuli in the color condition; all of them $(16 / 16 ; 100 \%)$ preferred the no-go color, consistent with their no-go type activity with the first set of stimuli.

At first sight, stronger activity for stimuli that require a go response, as in the go type $\mathrm{C}$ cells, might seem to signal the presence of a go target, not the absence of a no-go target. However, as can be seen in the activity pattern shown in Figure 2 (right panels), the go type $\mathrm{C}$ cell responded nondifferentially with increased activity to any target, instead of becoming silent, when the monkey attended to the motion direction of the target. We confirmed this tendency with population analysis of the 41 go type $\mathrm{C}$ cells with the first stimulus set (Fig. $4 A$ ). In the color condition, all target colors evoked activation at first, but $\sim 100$ msec after target presentation, suppression appeared on the activity evoked by a no-go color. In the motion condition, in contrast, there was no such suppression for targets with a no-go color. Thus, across all stimuli in both discrimination conditions, the only significant modulation observed was the suppression of the visually evoked activity to a no-go color in the color condition. Consequently, from the viewpoint of information processing, the only distinctive input that cells in the next processing stage (e.g., motor preparation) receive from the go type $\mathrm{C}$ cells is suppression of visual activity associated with targets that require a no-go response in the color condition. Interestingly, we could observe no obvious activity change during the actual motor suppression (the dimming period and pre-response period in no-go trials).

We also found $23 \mathrm{C}$ cells that selectively increased their activity to targets that require a no-go response (Fig. 3, left panel). These cells responded more to a no-go color than to a go color in the color condition, whereas they did not show a strong response to any target in the motion condition (Fig. 3, right panel). The population analysis based on these 23 no-go type $C$ cells indicated that the visual response to a target color associated with the no-go response was significantly enhanced in the color condition (Fig. $4 B$ ). Similar to the go type $\mathrm{C}$ cells, the only distinctive output from no-go type $\mathrm{C}$ cells toward later stages of information processing is associated with a no-go color in the color condition. Again, no activity change occurred during the manual motor suppression in this population.

To test the suppression and enhancement effects statistically, we calculated a task relevancy $(R)$ index that quantifies the effect of task relevancy of color by subtracting the visual responses of the cell in the motion condition from those in the color condition. The task relevancy index was calculated separately for go and 


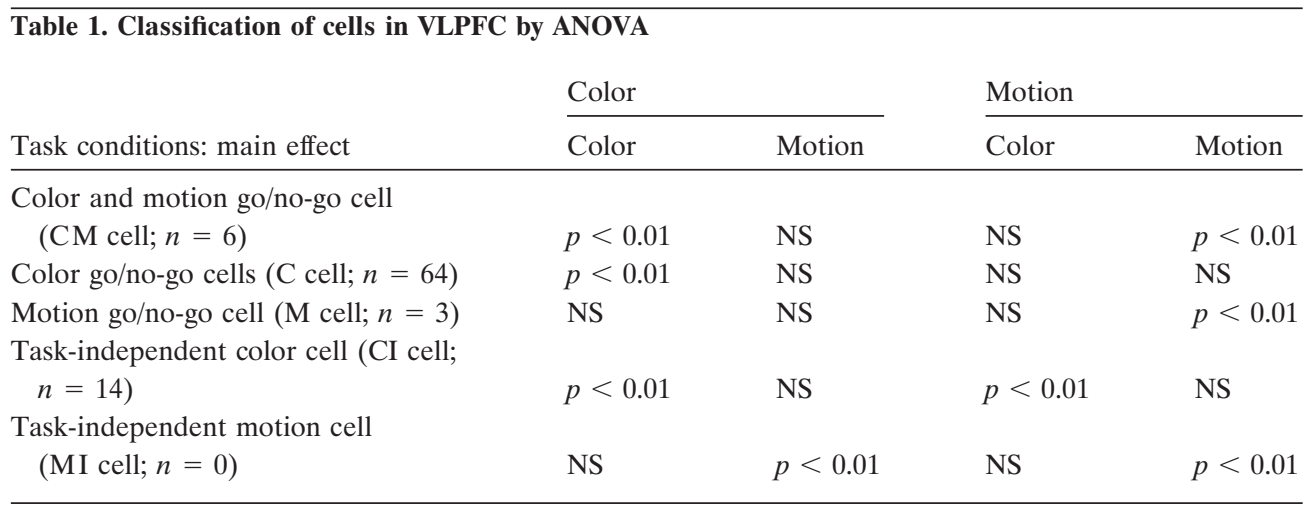

no-go colors. Figure $5 A$ shows the distributions of the index values for go type $\mathrm{C}$ cells, with the data for a go color on the left and a no-go color on the right. Negative values were obtained with a no-go color (mean $=-0.23 ; p<0.01$; two-tailed $t$ test against zero), whereas the values for a go color were not different from zero $($ mean $=0.06, \mathrm{NS})$, confirming that go type $\mathrm{C}$ cells selectively suppress their visual activity for targets with a no-go color in the color condition. On the other hand, for no-go type $\mathrm{C}$ cells (Fig. $5 B$ ), positive values were obtained with a no-go color (mean $=0.27 ; p<0.01)$, whereas the values for a go color were not different from zero (mean $=0.03$, NS), confirming that these cells enhanced their visual activity to targets with a no-go color in the color condition. Together, the results with go type and no-go type $\mathrm{C}$ cells indicate that the only modulation in the neuronal activity occurred with targets that required inhibition of the go response in the color condition.

Figure 6 indicates the locations of electrode penetrations in VLPFC (examples from two hemispheres). Go type and no-go type $\mathrm{C}$ cells were found in both left and right hemispheres. We also could not find any difference in depth. The distributions of the two types of $\mathrm{C}$ cells overlapped, indicating that they are not anatomically segregated within VLPFC.

\section{DISCUSSION}

The majority of visually responsive cells in VLPFC showed differential activity for go and no-go colors in the color condition, whereas they were nondifferential for colors as well as for motion directions in the motion condition ( $\mathrm{C}$ cells). This result is consistent with reports that neurons in VLPFC are selective for nonspatial visual stimuli (O'Scalaidhe et al., 1997, 1999). Approximately two-thirds of these $\mathrm{C}$ cells showed a higher firing rate for a go color than for a no-go color, and the remaining one-third preferred a no-go color. In previous research (Watanabe, 1986; Sakagami and Niki, 1994a; Sakagami and Tsutsui, 1999), the former type of cells was considered simply to reflect the process for generating a go response and the latter, a no-go response. Using our go/no-go task with multidimensional visual stimuli, however, we found that this view is incorrect. Instead, both types of cells change their neuronal activity specifically for colors that require behavioral inhibition.

One alternative interpretation of the activity of $\mathrm{C}$ cells would be that it reflects feature-selective (color-based) attention rather than processes during response selection. Indeed the VLPFC receives direct input from the ventral pathway of the visual association cortices (Barbas, 1988; Ungerleider et al., 1989) in which neuronal mechanisms of feature-selective attention have been reported (Motter, 1994; McAdams and Maunsell, 2000).
The C cells in the present study could share physiological properties with such cells in the visual association areas, responding specifically to the color dimension and showing task-dependent modulation. However, C cells in VLPFC show no differential activity for colors when the monkey attends to motion direction (Figs. 2-4, Table 1), whereas the neurons related to featureselective attention in the extrastriate visual cortices have a preference for a specific feature even when the feature is not attended to (Moran and Desimone, 1985; Motter, 1994; Treue and Martinez Trujillo, 1999; McAdams and Maunsell, 2000). In extrastriate visual areas, attention appears to improve the tuning curves to specific physical properties by relative enhancement of the signalto-noise ratio. In VLPFC, on the other hand, C cells show qualitatively different responses depending on the monkey's task. Importantly, when we checked the consistency of the go/no-go preference between the first and second set of stimuli, 94.7\% (18/19) of go type C cells and $100 \%$ (16/16) of no-go type C cells showed a consistent go/no-go preference, despite the strongly dissimilar physical properties of go colors and no-go colors from different stimulus sets (see Materials and Methods). These data suggest that C cells in VLPFC classify stimuli by their behavioral meaning rather than by their physical properties. In addition, other studies have shown that many cells in LPFC, including VLPFC, code behavioral significance rather than sensory features in stimulus-response reversal tasks or in new learning situations (Niki et al., 1990; Asaad et al., 1998). Thus it seems plausible that $\mathrm{C}$ cells perform a function that is more closely related to selecting the appropriate action than the sensory mechanisms of feature-based attention in extrastriate visual areas.

With the comparison across attention conditions, it becomes clear that both go type and no-go type $\mathrm{C}$ cells change their activity selectively for a no-go color in the color condition, taking the nondifferential activity in the motion condition as a reference level. Go type $\mathrm{C}$ cells do so by suppressing their activity for a no-go color as compared with the nondifferential activity in the motion condition; in turn, no-go type $\mathrm{C}$ cells enhance their activity for a no-go color in the color condition. Thus, both types of $\mathrm{C}$ cells have distinctive output only on no-go trials in the color condition, and so we can propose that they contribute to the control of behavior by indicating which color stimuli require suppression of the go response.

It is expected that the loss of such VLPFC cells would lead to inability to refrain from making a go response on no-go trials. This may actually have been observed in lesion studies with monkeys (Butter, 1969; Iversen and Mishkin, 1970; Butters et al., 


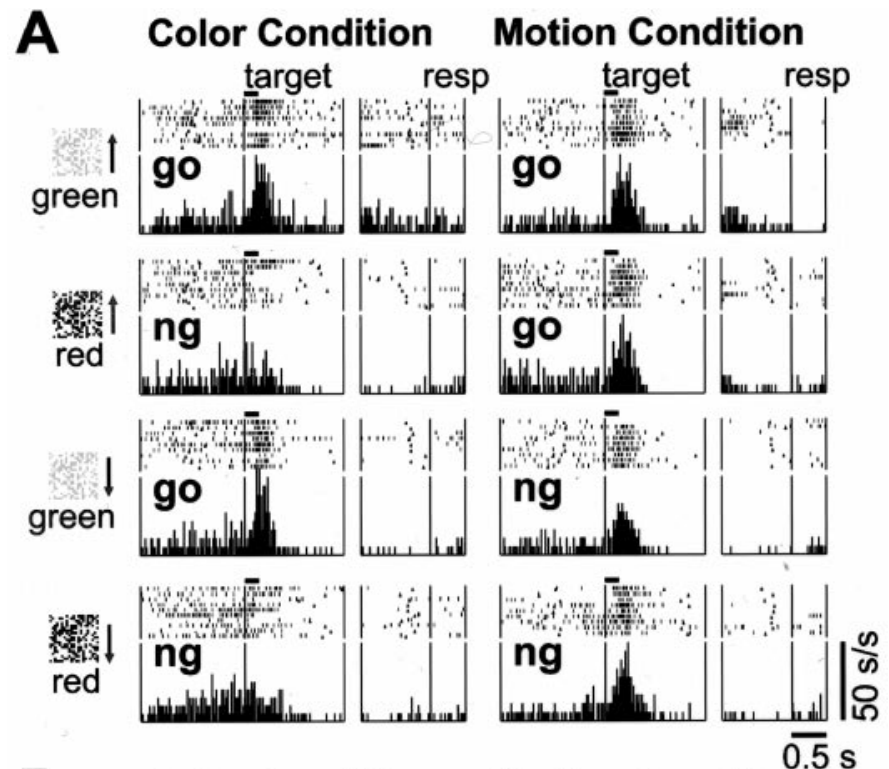

B Color Condition Motion Condition

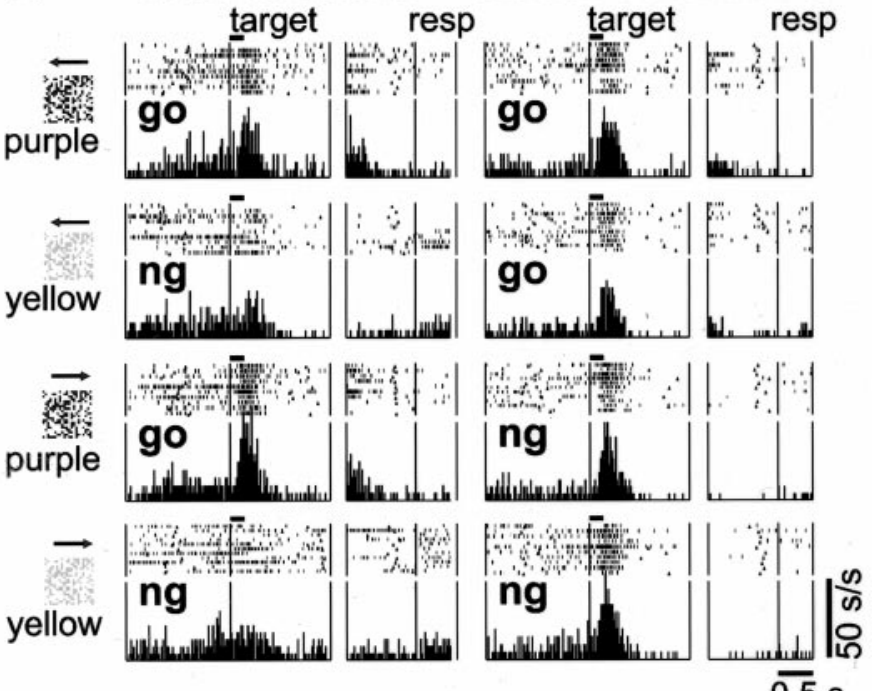

$\overline{0.5 \mathrm{~s}}$

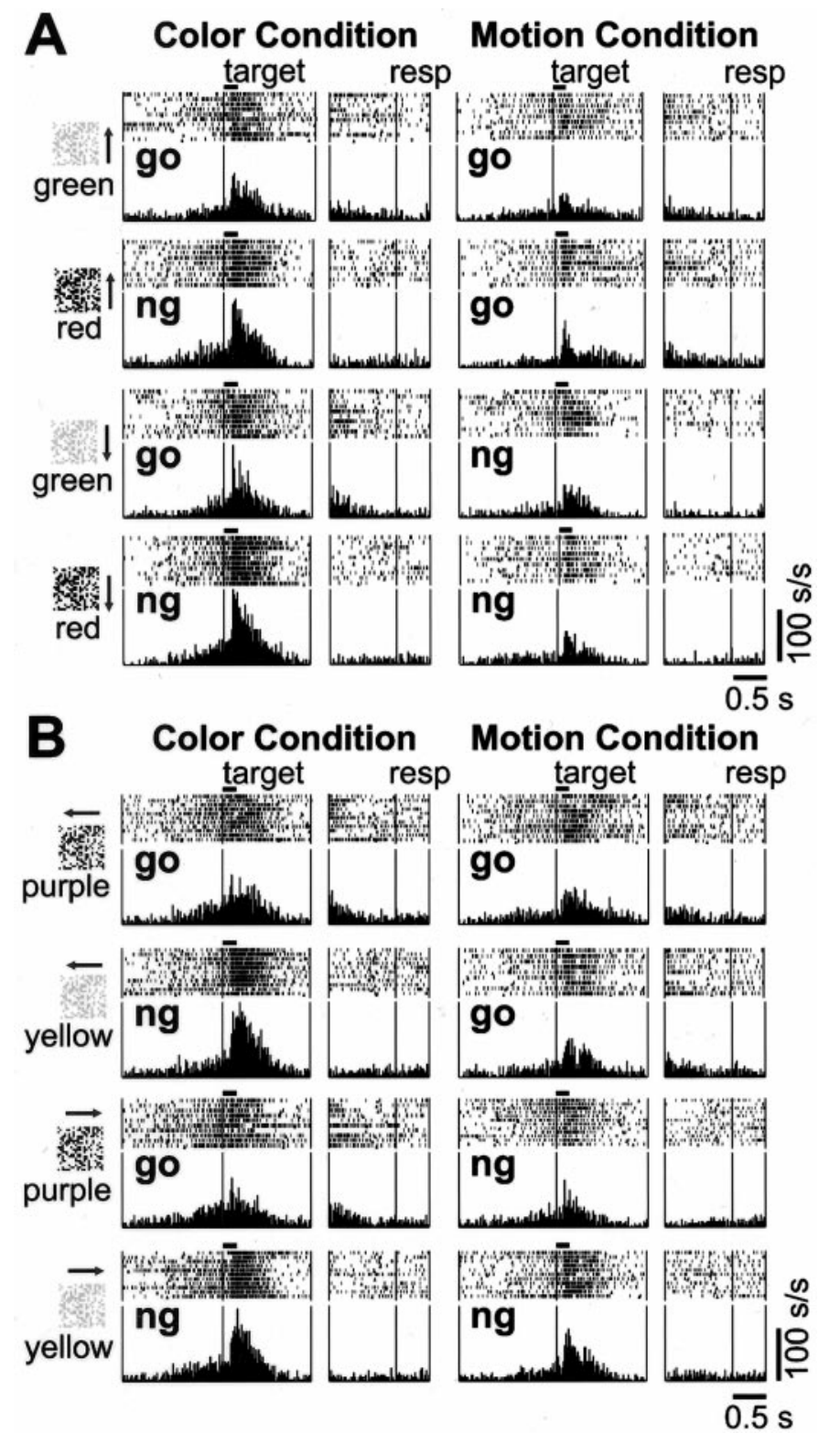

Figure 3. Activity pattern of the no-go type $\mathrm{C}$ cell. $A$, Typical example of a no-go type $\mathrm{C}$ cell with the first set of stimuli. $B$, Activity pattern of the same cell with the second set of stimuli.

monkey, with the inability to suppress inappropriate responses in given circumstances (Fuster, 1997; Robbins, 1998). In support of this proposition, recent functional imaging studies reported activation of regions specific to response inhibition in the inferior PFC of humans, thus suggesting a correspondence with VLPFC in monkeys (Jonides et al., 1998; Nagahama et al., 1998; Konishi et al., 1999; Shadmehr and Holcomb, 1999).

From these lesion or functional imaging studies, however, it is not clear whether the loss of inhibitory control after damage to VLPFC is caused by an inability of motor control or a cognitive deficit during stimulus-response association. Two aspects of our current data strongly suggest that the deficit occurs at a cognitive stage before motor control. First, the population analysis in our study revealed that there were no activity changes related to the actual execution of motor responses, neither around dimming of the fixation spot (at which time the monkey should refrain from
Stuss and Benson, 1986; Shimamura, 1994). This dysfunction seems to have the same structure as the behavioral deficits in
1973), and humans (Perret, 1974; Drewe, 1975; Lhermitte et al., 1986). Iversen and Mishkin (1970) reported that monkeys with a esion of VLPFC, or the inferior convexity, could not suppress go behavior in response to auditory or visual targets on no-go trials, despite their intact sensory and motor abilities. In humans, perseveration is a common deficit after lesion of PFC (Milner, 1964;

Figure 2. Activity pattern of the go type C cell. A, Typical example of a left. The rasters and histograms are split in two; the left side is aligned on target onset (vertical line; the horizontal bar indicates target duration), and correct trials were obtained. The left panel represents the neuronal activcondition. Arrows in the stimuli indicate motion direction. go, Go trial; ng, illumination (end of dim): fixation dimming in the target-aligned rasters the go trials of response-aligned rasters, and re-illumination of response-aligned rasters. Bin width, $20 \mathrm{msec}$. $B$, Activ pattern of the same cell with the second set of stimuli. 
A

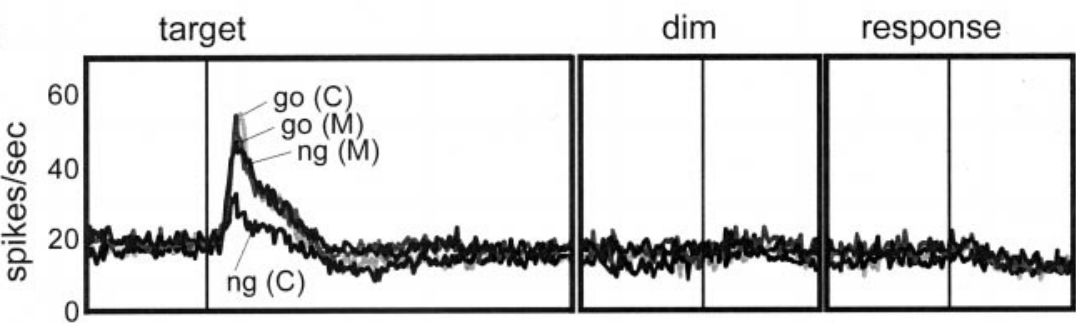

Figure 4. Population average of two types of $\mathrm{C}$ cells. $A$, Population average of 41 go type $\mathrm{C}$ cells to the target onset (left panel), onset of the fixation dimming (middle panel), and lever release (right panel). The line indicated by $g o(C)$ shows the response to the go color in the color condition; $n g(C)$, the response to the no-go color in the color condition; go $(M)$, the response to the go color in the motion condition; $n g(M)$, the response to the no-go color in the motion condition (collapsed across motion directions). The curves are based on nonsmoothed data with $10 \mathrm{msec}$ temporal resolution. $B$, Population average of 23 no-go type

B

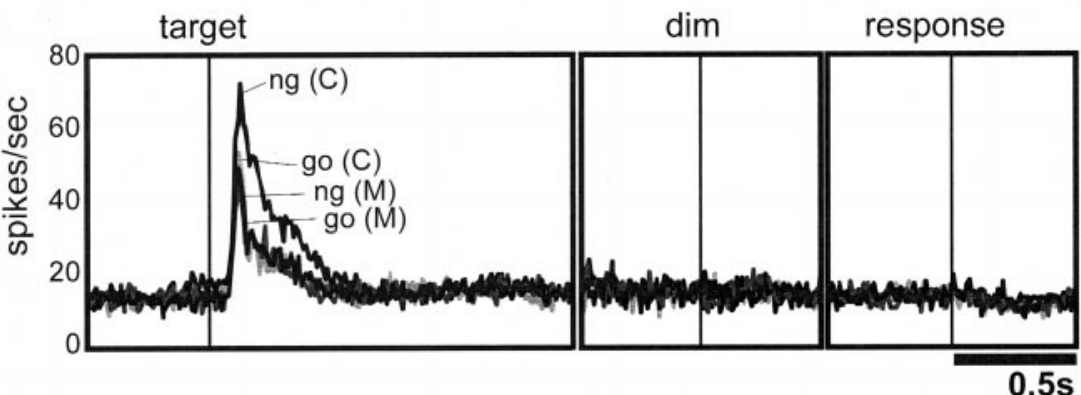
C cells.

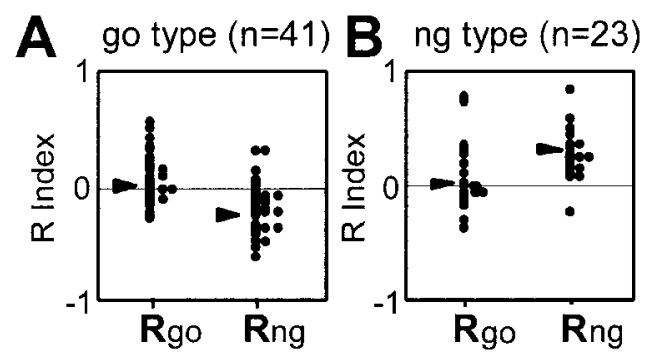

Figure 5. Plots of the task relevancy $(R)$ index, presented for go type $\mathrm{C}$ cells $(A)$ and no-go type $C$ cells $(B)$. In both panels, plots on the left show indices for the go color $\left(R_{g o}\right)$, and plots on the right show indices for the no-go color $\left(R_{n g}\right)$. Positive values indicate enhancement of the response in the color condition relative to the motion condition; negative values indicate suppression in the color condition. Arrowheads indicate the mean values of the distributions.

releasing the lever in a no-go trial) nor around lever release (after fixation dimming in a go trial; after fixation re-illumination in a no-go trial). This was true for both go type and no-go type $\mathrm{C}$ cells (Fig. 4). It was only immediately after target onset that both types of cells supplied distinct information concerning colors that were associated with a no-go response. They ceased responding within $500 \mathrm{msec}$ after target onset, whereas the fixation dimming occurred at least $500 \mathrm{msec}$ after target onset, suggesting that VLPFC conveys the information about behavioral significance to other areas, which in turn would be responsible for the motor preparation or execution, or both.

Second, the fact that the go/no-go differential activity was specific for the color dimension also proves that the present data do not reflect the last stages of motor preparation or execution of the manual responses, but rather the cognitive processes involved in the inhibitory control of behavior (Hauser, 1999). Interestingly, the data with different stimulus sets further show that the go/ no-go differential activity is not specific to particular color features (Figs. 2, 3), suggesting that the neuronal activity does not simply reflect sensory features either. Rather, VLPFC neurons appear to group together colors that require behavioral inhibition (in this experiment, red and yellow). This activity is described best as a dimension-specific code for behavioral inhibition.

Indeed, $\sim 87.7 \%$ of go/no-go discriminating cells in VLPFC

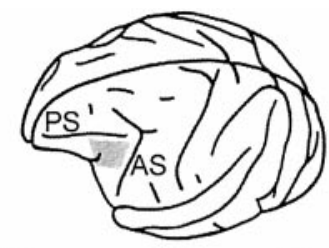

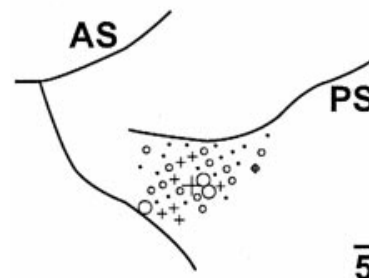

Monkey \#1
Right hemisphere
Monkey \#2 Left hemisphere

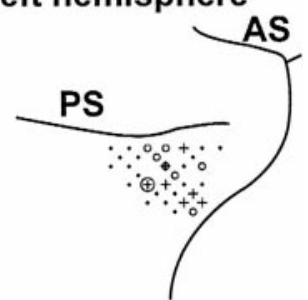

Figure 6. Examples of electrode penetrations in two monkeys (right hemisphere from Monkey \#1 and left hemisphere from Monkey \#2). Similar distributions were observed in the other hemispheres (data not shown). Circles indicate go type C cells; plus signs indicate no-go type C cells. Small symbols indicate one cell; large symbols indicate two cells. A circle superimposed on a plus sign indicates a location in which both types of $\mathrm{C}$ cells were found. In penetrations indicated by small dots, no $\mathrm{C}$ cells were found. $P S$, Principal sulcus; $A S$, arcuate sulcus. The inset is a lateral view of the left hemisphere and shows the location of VLPFC ( gray area).

distinguished between targets on the basis of color but not motion direction. This result is consistent with anatomical data (Barbas, 1988; Ungerleider et al., 1989) suggesting that the afferent connections to VLPFC are stronger from inferotemporal cortex than from parietal cortex, including lateral intraparietal, medial superior temporal, and middle temporal. These parietal areas, which are closely related to visual motion processing, project mainly onto the dorsolateral and arcuate prefrontal areas (Andersen et al., 1990; Schall et al., 1995). One question, then, is whether dorsolateral prefrontal neurons have analogous properties with regard to inhibitory control, perhaps for more dorsal visual dimensions such as spatial position or motion direction. It is known, for example, that dorsolateral prefrontal cortex is involved in the control of anti-saccades, which require the suppression of a prepotent eye movement (Funahashi et al., 1993). On the other hand, 
the lesion and functional imaging studies cited above have suggested a stronger role for ventrolateral than for dorsolateral prefrontal cortex in inhibitory control. Further investigation may resolve this issue using the rationale of the present experimental paradigm in dorsolateral prefrontal cortex.

The color-specific inhibitory control in VLPFC extends the hypothesis regarding the segregation of visual processing streams even in the PFC (Goldman-Rakic, 1987; Wilson et al., 1993; Sakagami and Tsutsui, 1999). For the conversion of spatial information into motor commands, the dorsal pathway may use the strong connection between parietal cortex and the premotor cortex (Goodale and Milner, 1992; Wise et al., 1997). To convert color or shape information into appropriate behavior, on the other hand, the ventral pathway does not send its information directly from inferotemporal cortex to the premotor or primary motor area. Instead, the ventral pathway passes through the PFC before reaching the premotor cortex (Barbas, 1988; Lu et al., 1994; Boussaoud et al., 1996). The function of PFC, particularly VLPFC, in the ventral stream of information processing is to attach behavioral meaning to the color or shape information (Watanabe, 1986; Yajeya et al., 1988; Sakagami and Tsutsui, 1999). The present data, combined with earlier lesion studies, suggest that this behavioral code serves to exert inhibitory control. In this way, motor programming can respond more flexibly to changing values of stimuli in the environment.

\section{REFERENCES}

Andersen RA, Asanuma C, Siegel RM (1990) Corticocortical connections of anatomically and physiologically defined subdivisions within the inferior parietal lobule. J Comp Neurol 296:65-113.

Asaad WF, Rainer G, Miller EK (1998) Neural activity in the primate prefrontal cortex during associative learning. Neuron 21:1399-1407.

Barbas H (1988) Anatomic organization of basoventral and mediodorsal visual recipient prefrontal regions in the rhesus monkey. J Comp Neurol 276:313-342.

Boussaoud D, di Pellegrino G, Wise SP (1996) Frontal lobe mechanisms subserving vision-for-action versus vision-for-perception. Behav Brain Res 72:1-15.

Butter CM (1969) Perseveration in extinction and in discrimination reversal tasks following selective frontal ablations in Macaca mulatta. Physiol Behav 4:163-171.

Butters N, Butter C, Rosen J, Stein D (1973) Behavioral effects of sequential and one-stage ablations of orbital prefrontal cortex in the monkey. Exp Neurol 39:204-214.

Dias R, Robbins TW, Roberts AC (1996) Dissociation in prefrontal cortex of affective and attentional shifts. Nature 380:69-72.

Drewe EA (1975) Go-no go learning after frontal lobe lesions in humans. Cortex 11:8-16.

Ferrera VP, Cohen JK, Lee BB (1999) Activity of prefrontal neurons during location and color delayed matching tasks. NeuroReport 10:1315-1322.

Funahashi S, Chafee MV, Goldman-Rakic PS (1993) Prefrontal neuronal activity in rhesus monkeys performing a delayed anti-saccade task. Nature 365:753-756.

Fuster JM (1997) The prefrontal cortex: anatomy, physiology, and neurophysiology of the frontal lobe, Ed 3. New York: Lippincott-Raven.

Goldman-Rakic PS (1987) Circuitry of primate prefrontal cortex and regulation of behavior by representational memory. In: Handbook of physiology, Vol 5: the nervous system, higher functions of the brain, Part 1 (Plum F, ed), pp 373-417. Bethesda, MD: American Physiological Society.

Goodale MÁ, Milner AD (1992) Separate visual pathways for perception and action. Trends Neurosci 15:20-25.

Guitton D, Buchtel HA, Douglas RM (1985) Frontal lobe lesions in man cause difficulties in suppressing reflexive glances and in generating goal-directed saccades. Exp Brain Res 58:455-472.

Hauser MD (1999) Perseveration, inhibition and the prefrontal cortex: a new look. Curr Opin Neurobiol 9:214-222.

Iversen SD, Mishkin M (1970) Perseverative interference in monkeys following selective lesions of the inferior prefrontal convexity. Exp Brain Res 11:376-386.

Jonides J, Smith EE, Marshuetz C, Koeppe RA, Reuter-Lorenz PA (1998) Inhibition in verbal working memory revealed by brain activation. Proc Natl Acad Sci USA 95:8410-8413.
Kim JN, Shadlen MN (1999) Neural correlates of a decision in the dorsolateral prefrontal cortex of the macaque. Nat Neurosci 2:176-185.

Knight RT, Staines WR, Swick D, Chao LL (1999) Prefrontal cortex regulates inhibition and excitation in distributed neural networks. Acta Psychol 101:159-178.

Komatsu H (1982) Prefrontal unit activity during a color discrimination task with GO and NO-GO responses in the monkey. Brain Res 244:269-277.

Konishi S, Nakajima K, Uchida I, Kikyo H, Kameyama M, Miyashita Y (1999) Common inhibitory mechanism in human inferior prefrontal cortex revealed by event-related functional MRI. Brain 122:981-991.

Lauwereyns J, Koizumi M, Sakagami M, Hikosaka O, Kobayashi S, Tsutsui K (2000) Interference from irrelevant features on visual discrimination by macaques (Macaca fuscata): a behavioral analogue of the human Stroop effect. J Exp Psychol Anim Behav Process 26:352-357

Leon MI, Shadlen MN (1999) Effect of expected reward magnitude on the response of neurons in the dorsolateral prefrontal cortex of the macaque. Neuron 24:415-425.

Lhermitte F, Pillon B, Serdaru M (1986) Human autonomy and the frontal lobes. Part II: Imitation and utilization behavior: a neuropsychological study of 75 patients. Ann Neurol 19:326-334.

Lu MT, Preston JB, Strick PL (1994) Interconnections between the prefrontal cortex and the premotor areas in the frontal lobe. J Comp Neurol 341:375-392.

Luria AR (1966) Higher cortical functions in man. New York: Basic Books.

McAdams CJ, Maunsell JH (2000) Attention to both space and features modulates neuronal responses in macaque area V4. J Neurophysiol 83:1751-1755.

Milner B (1964) Some effects of frontal lobectomy in man. In: The frontal granular cortex and behavior (Warren JM, Akert K, eds), pp 313-334. New York: McGraw-Hill.

Mishkin M, Manning FJ (1978) Non-spatial memory after selective prefrontal lesions in monkeys. Brain Res 143:313-323.

Moran J, Desimone R (1985) Selective attention gates visual processing in the extrastriate cortex. Science 229:782-784.

Motter BC (1994) Neural correlates of attentive selection for color or luminance in extrastriate area V4. J Neurosci 14:2178-2189.

Nagahama Y, Sadato N, Yamauchi H, Katsumi Y, Hayashi T, Fukuyama H, Kimura J, Shibasaki H, Yonekura Y (1998) Neural activity during attention shifts between object features. NeuroReport 9:2633-2638.

Niki H, Sugita S, Watanabe M (1990) Modification of the activity of primate frontal neurons during learning of a GO/NO-GO discrimination and its reversal: a progress report. In: Vision, memory, and the temporal lobe (Iwai E, Mishkin M, eds), pp 295-304. New York: Elsevier.

O’Scalaidhe SP, Wilson FAW, Goldman-Rakic P (1997) Areal segregation of face-processing neurons in prefrontal cortex. Science 278:1135-1138.

O'Scalaidhe SP, Wilson FAW, Goldman-Rakic P (1999) Face-selective neurons during passive viewing and working memory performance of rhesus monkeys: evidence for intrinsic specialization of neuronal coding. Cereb Cortex 9:459-475.

Passingham RE (1975) Delayed matching after selective prefrontal lesions in monkeys (Macaca mulatta). Brain Res 92:89-102.

Passingham RE (1998) Attention to action. In: The prefrontal cortex: executive and cognitive functions (Roberts AC, Robbins TW, Weiskrantz L, eds), pp 131-143. New York: Oxford UP.

Perret E (1974) The left frontal lobe of man and the suppression of habitual responses in verbal categorical behaviour. Neuropsychology 12:323-330.

Rainer G, Asaad WF, Miller EK (1998) Selective representation of relevant information by neurons in the primate prefrontal cortex. Nature 393:577-579.

Robbins TW (1998) Dissociating executive functions of the prefrontal cortex. In: The prefrontal cortex: executive and cognitive functions (Roberts AC, Robbins TW, Weiskrantz L, eds), pp 117-130. New York: Oxford UP.

Sakagami M, Niki H (1994a) Encoding of behavioral significance of visual stimuli by primate prefrontal neurons: relation to relevant task conditions. Exp Brain Res 97:423-436.

Sakagami M, Niki H (1994b) Spatial selectivity of go/no-go neurons in monkey prefrontal cortex. Exp Brain Res 100:165-169.

Sakagami M, Tsutsui K (1999) The hierarchical organization of decision making in primate prefrontal cortex. Neurosci Res 34:79-89.

Schall JD, Hanes DP (1993) Neural basis of saccade target selection in frontal eye field during visual search. Nature 366:467-469.

Schall JD, Morel A, King DJ, Bullier J (1995) Topography of visual cortex connections with frontal eye field in macaque: convergence and segregation of processing streams. J Neurosci 15:4464-4487.

Shadmehr R, Holcomb HH (1999) Inhibitory control of competing motor memories. Exp Brain Res 126:235-251. 
Shimamura AP (1994) Memory and the frontal lobe. In: The cognitive neurosciences (Gazzaniga MS, ed), pp 803-813. Cambridge, MA: MIT.

Stuss DT, Benson DF (1986) The frontal lobes. New York: Raven Press. Tremblay L, Schultz W (1999) Relative reward preference in primate orbitofrontal cortex. Nature 398:704-708.

Treue S, Martinez Trujillo JC (1999) Feature-based attention influences motion processing gain in macaque visual cortex. Nature 399:575-579.

Ungerleider LG, Gaffan D, Pelak VS (1989) Projections from inferior temporal cortex to prefrontal cortex via the uncinate fascicle in rhesus monkeys. Exp Brain Res 76:473-484.

Watanabe M (1986) Prefrontal unit activity during delayed conditional Go/No-Go discrimination in the monkey. I. Relation to the stimulus. Brain Res 382:1-14.
Watanabe M (1996) Reward expectancy in primate prefrontal neurons. Nature 382:629-632.

Wilson FAW, O'Scalaidhe SP, Goldman-Rakic PS (1993) Dissociation of object and spatial processing domains in primate prefrontal cortex. Science 260:1955-1958.

Wise SP, Boussaoud D, Johnson PB, Caminiti R (1997) Premotor and parietal cortex: corticocortical connectivity and combinatorial computations. Annu Rev Neurosci 20:25-42.

Yajeya J, Quintana J, Fuster JM (1988) Prefrontal representation of stimulus attributes during delay tasks. II. The role of behavioral significance. Brain Res 474:222-230.

Yamatani K, Ono T, Nishijo H, Takaku A (1990) Activity and distribution of learning-related neurons in monkey (Macaca fuscata) prefrontal cortex. Behav Neurosci 104:503-531. 